\title{
FUZZY LOGIC BASED ENERGY HARVESTING WITH THE MOVEMENT OF PLANTS BRANCHES AND LEAVES
}

\author{
Basit Ali' ${ }^{1}$, Muhammad Waseem Ashraf ${ }^{1, *}$, Shahzadi Tayyaba ${ }^{2}$, Muhammad Zahid Qureshi ${ }^{1}$, \\ Ghulam Sarwar', Muhammad Faisal Wasim ${ }^{1}$ and Nitin Afzulpurkar ${ }^{3}$ \\ ${ }^{1}$ GC University, Lahore, Pakistan; ${ }^{2}$ The University of Lahore, Pakistan; ${ }^{3}$ Asian Institute of Technology, Bangkok, \\ Thailand. \\ "Corresponding author's e-mail: Muhammad.Waseem.Ashraf@gmail.com
}

\begin{abstract}
Energy crisis is increasing day by day around the globe due to overconsumption, overpopulation, wastage of energy, poor infrastructure, and delay in commissioning of power plants, unexplored renewable energy resources and techniques. There is an urgent need to find out the new ways of energy production and utilization techniques. Here, authors present the new technique of energy harvesting with the movement of plant's branches and leaves. Simulation and design algorithm of energy harvesting system has been presented. Electricity can be produced due to air pressure on piezo nanogenerator that can be installed on branches and leaves of plants. The effect of variation in inputs on the range of outputs has been studied. Fuzzy Logic tool in MATLAB and Mamdani's model have been used for the simulation and calculation. Air velocity and angle have been considered as the two inputs and power has been considered as output of this energy harvesting system. Three membership functions for the inputs and output parameters have been allotted. The energy harvesting system works according to the specific defined rules. The variations of the inputs and the outputs have been displayed on the surface viewer graphs. The results obtained by fuzzy based simulation and Mamdani's model based calculations have only $0.27 \%$ error. This shows that the proposed energy harvesting system will perform well.
\end{abstract}

Keywords: Agriculture, AND logic, energy harvesting system, FIS, MFs, MATLAB, Mamdani's formula, Piezoelectricity.

\section{INTRODUCTION}

Energy crisis is one of the top most problems around the world which needs to be solved immediately. Due to the overpopulation, worldwide energy resources are reducing. In this period of energy crisis we should discover such energy harvesting system that can produce electricity in the cleanest, simplest and easiest way. Pakistan is considered to be a lower middle income country with total population of 182.5 million and GDP 236.5 \$ (Javed et al., 2015). Therefore, we are trying to discover such energy harvesting systems that can easily produce electrical energy by the motion of the branches and leaves of the trees due to air flows through them and by the phenomenon of piezoelectricity. The researchers in the world are trying their best to promote such kind of energy harvesting system so that the energy crisis in the world could be controlled. Clean and cheap energy is the utmost desire of the scientists, therefore, they are trying to develop new methods (Kamat, 2007). Renewable energy sources are to be established in near future to replace the coal power plants and fossil fuel. It will reduce the $\mathrm{CO}_{2}$ emission and thus making the environment more human friendly (Lund et al., 2015). The quantum efficiency of photosynthetic plants is about $100 \%$ because all the photons may be converted into electrons. Thylakoids are responsible for capturing and transferring electrons from the plants (Liu, 2016). A PIMNT piezoelectric energy harvest is studied for brain stimulation in mice. In this device the PIMNT material was grown on plastic substrate which generated $0.57 \mathrm{~mA}$ current with a slight bending (Hwang et al., 2015). Cha et al. (2016) has investigated the energy harvesting from the tail motion of biomimetic fish using the piezoelectric materials. They claimed that the underwater tail vibration could be used to produce electricity by using piezoelectric effect. In order to power the air craft electronic system, an energy harvesting has been studied using the piezoelectric material. Piezoelectric transducer converts the air flow energy into electric energy which may be utilized by the electronic system of the air craft (Zou et al., 2015). Xie et al. (2015) has introduced the piezoelectric methodology for energy harvesting from the vibrations of high-rise buildings, the energy harvesting system also dissipates vibrations of such buildings. Ilyas and Swingler (2015) developed a piezoelectric device to utilize the impact of raindrop vibrational motion on it and produced the electrical energy. Impact of raindrop on the piezoelectric device is studied for various heights. The proposed energy producing system is one of the most important devices for producing electricity by the motion and movements of the branches and leaves of the trees with the help of piezoelectric effect known as piezoelectricity. Some other phenomenon occurring in nature could be used to produce electric energy by using piezoelectricity like walking, running, dancing, heart beating and breathing. The mechanical work or the to and fro motion and human activity is the best source to produce 
electrical energy through piezoelectric energy harvesting system. Energy can be easily produced by human walking with piezoelectric devices which can provide enough power to the wireless electronic devices (Donelan et al., 2008). Nanogenerators using piezoelectric can be produced with simple fabrication technology. These nanogenerators can be optimized to achieve the voltage over $37 \mathrm{~V}$ by controlling the material and structural properties. These nanogenerators can power up small electronics devices and sensors (Hu and Wang, 2015). A method was presented for the establishment and maximization of an electret generator which means vibration-to-electric micro converter. The motion of the converter was examined in detail which showed the need of the maximization process (Peano and Tambosso, 2005). The available power can be increased by 10-100's of W by using piezoelectric effect. There is a limitation of the piezoelectric harvesters in their interface circuit which must be required in order to obtain four times output power. The different researchers of the world reviewing the application of renewable energy system and in their review articles they concluded that fuzzy logic based model gave the realistic approach (Suganthi et al., 2015). A hybrid power source with a combination battery and fuel cell has been studied using fuzzy logic control system. A vibrational energy harvester is designed for driving a biologging device. This energy harvester was mounted to flying vertebrates which generated sufficient energy to run a biologging device (Shafer et al., 2015). Now a day's peoples are establishing a model of fuzzy clustering system for farm administration and for the better usage of energy. In their study they successfully demonstrated the application of fuzzy logic approach for better use of energy in wheat cultivation system (Khoshnevisan et al., 2015). Scientists in the world are investigating the amount of energy and power available from the motion of the trees for the last decades. They measured the horizontal acceleration (a) and the angular deflection $(\theta)$ of the free motion of the trunk and found that this energy and power produced during the back and forth motion of the leaves and branches of the trees can be used to run a wireless sensor node and lighting systems (McGarry and Knight, 2011). Fuzzy logic controller is used in tracking the direction of maximum wind speed. The direction of maximum wind speed is sensed, it used as reference and wind turbine head is moved towards the direction of maximum wind speed to get the maximum power (Bharani and Jayasankar, 2015). In an automatic milk pipe line washing and milk preservative system fuzzy logic system can also be used (Yasmeen and Khan, 2013). Here, authors present the fuzzy logic based system for energy harvesting.

\section{DESIGN METHODOLOGY}

Design methodology can be discussed under the following headings,
Energy harvesting mechanism: Piezoelectric nano energy generator can be installed on the branches and leaves of trees and plants. Energy harvesting is due to the free motion of the branches and leaves of the trees. When air exerts pressure on sensor or piezonano generator then it compressed and with expansion it produces voltage. The speed of the gentle breeze and moderate breeze is 3.3-5.5 $\mathrm{m} / \mathrm{s}$ and $5.5-8 \mathrm{~m} / \mathrm{s}$, respectively. The mechanical power produced by the figure motion is $6.9-19 \mathrm{~mW}$ and this power can be converted into 1.2-3.2 $\mathrm{mW}$ electrical power. The electrical energy produced per movement is $226-406 \mu \mathrm{J}$. In order to produce this energy by the motion of the leaves and branches of the trees is possible only if they move to and fro only by $20 \mathrm{~cm}$ and the force exerted by the breeze on it $2 \times 10^{-6} \mathrm{~N}$. The mass of the air blows per unit time must be $0.46 \mathrm{~g} / \mathrm{s}$ and we know $1 \mathrm{~m}^{3}$ volume of air contains $10^{23}$ to $10^{25}$ atoms or molecules of a gas. The mass of $10^{23}$ atoms of $\mathrm{N}_{2}, \mathrm{O}_{2}$, or $\mathrm{H}_{2}$ is about $0.16 \mathrm{~g}$, therefore, about 4 times of this mass of air would be able to produce an electrical power that will be able to drive a led. Hence in this way we can easily produce electrical energy which is clean, cheap easy way to overcome the energy crisis in the world. The Figure 1 and 2 showing different orientations of the air striking the leaves and branches of the trees and we observe that maximum power will be produced if the air strikes at an angle of $90^{\circ}$.

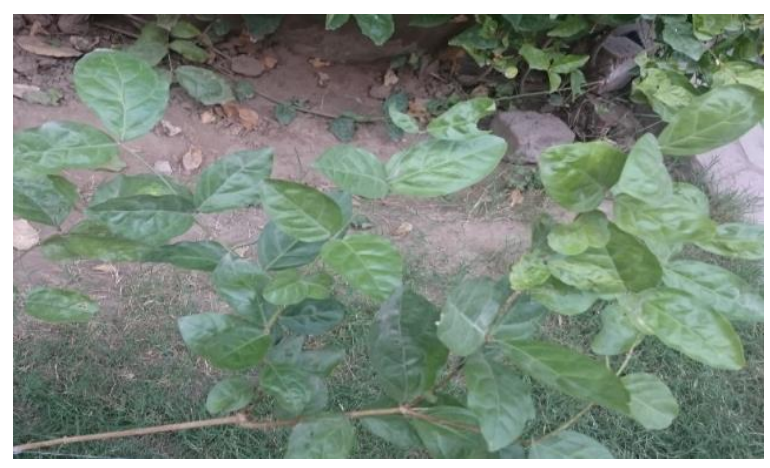

Figure 1. Surface of the leave on which the air blows.

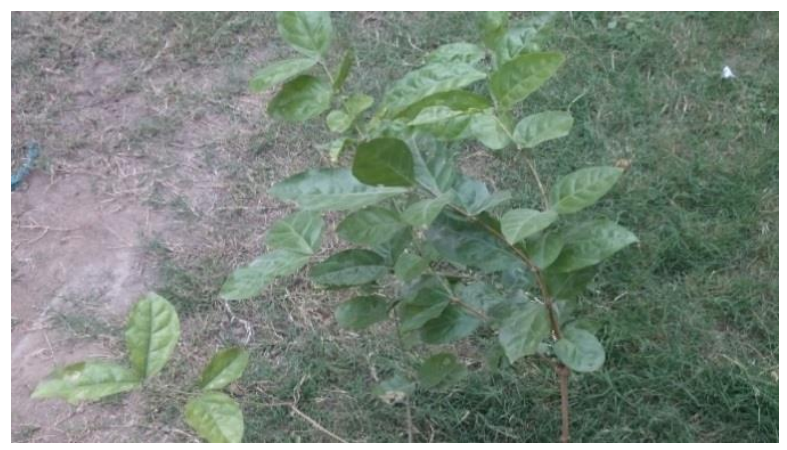

Figure 2. Bending of the leave by the air.

Energy harvesting simulation: In MATLAB designing, FLC consists of two input and single output variables with 


\section{Ali, Ashraf, Tayyaba, Qureshi, Sarwar, Wasim \& Afzulpurkar}

three membership functions in each variable. Two input variables air velocity and angle, and a single output variable power are shown in Figure 3.

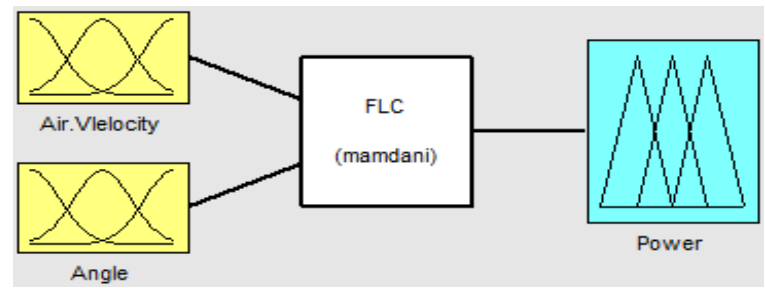

Figure 3. Fuzzy Logic controller.

Fuzzy Logic Controller (FLC) can be used in Fuzzy Logic Inferring System (FIS) for the selection of inputs. We have used only two inputs and each input consists of three membership functions (MFs). The ranges should be selected in such a way that the proposed values of input (MFs) and output (MFs) must overlap each other because this is the basic condition for Fuzzy Logic System. The range of the input air velocity is $0-100$ and that of the angle is $0-180^{\circ}$, and the range of the output has been taken as $0-100$. The details are shown in the Table 1 .

Table 1. Ranges of the inputs and output.

\begin{tabular}{|c|c|c|c|c|}
\hline MFs & Ranges & $\begin{array}{c}\text { Air } \\
\text { Velocity }\end{array}$ & Angle & Power \\
\hline $\mathrm{MF}_{1}$ & $\begin{array}{c}0-50 \\
0-90^{\circ}\end{array}$ & $\begin{array}{c}\text { Slow } \\
(\mathrm{S})\end{array}$ & $\begin{array}{c}\text { Acute } \\
(\mathrm{A})\end{array}$ & $\begin{array}{c}\text { Low } \\
(\mathrm{L})\end{array}$ \\
\hline $\mathrm{MF}_{2}$ & $\begin{array}{c}0-100 \\
0-180^{\circ}\end{array}$ & $\begin{array}{c}\text { Fast } \\
(\mathrm{F})\end{array}$ & $\begin{array}{c}\text { Right } \\
(\mathrm{R})\end{array}$ & $\begin{array}{c}\text { Medium } \\
(\mathrm{M})\end{array}$ \\
\hline $\mathrm{MF}_{3}$ & $\begin{array}{c}50-100 \\
90-180^{\circ}\end{array}$ & $\begin{array}{c}\text { Gale } \\
(\mathrm{G})\end{array}$ & $\begin{array}{c}\text { Obtuse } \\
(\mathrm{O})\end{array}$ & $\begin{array}{c}\text { High } \\
(\mathrm{H})\end{array}$ \\
\hline
\end{tabular}

The common regions have been differentiated in Figure 4. The first overlapping region is from 0 to 50 for air velocity and power but for angle it is from 0 to $90^{\circ}$ and is named as Region 1. The second overlapping region is from 50 to 100 for air velocity and power but for angle it is from 90 to $180^{\circ}$ and is named as Region 2.

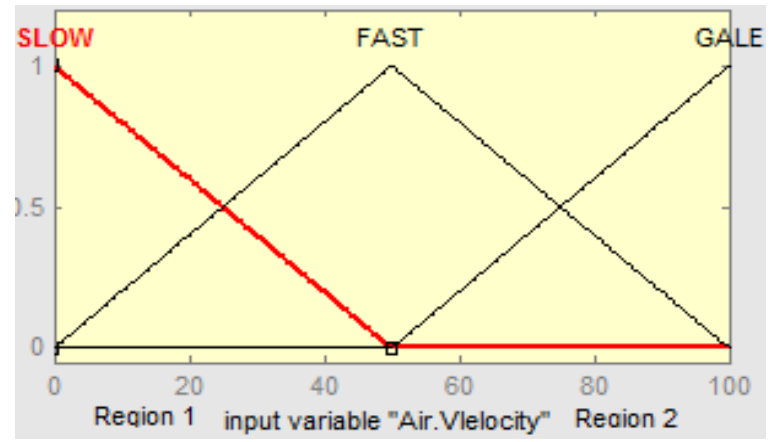

Figure 4. Division of the regions.
In designing this system different rules have been consider for the improvement of the result. IF - AND - THEN statement have been applied for fuzzy logic rule analysis. Membership functions for the input variables air velocity and angle are shown in Figure 5 and 6. For the output variable power, the membership functions are shown in Figure 7.

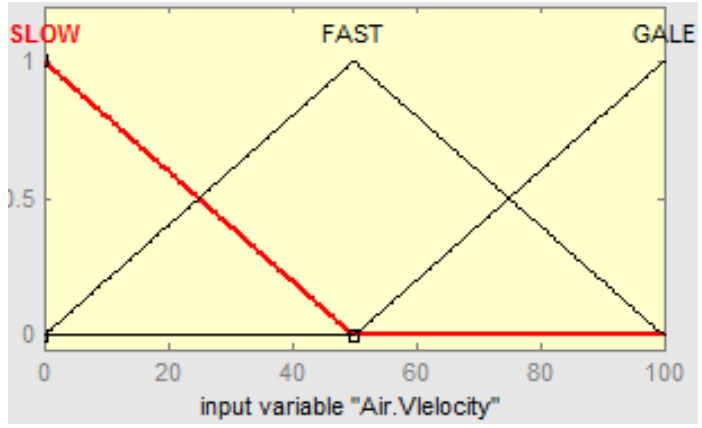

Figure 5. Membership functions for air velocity.

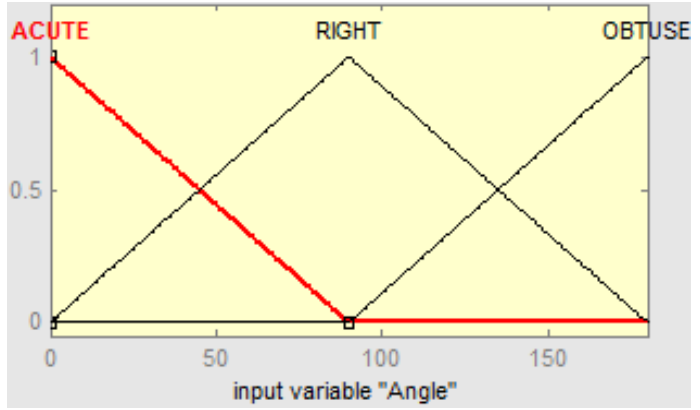

Figure 6. Membership functions for angle.

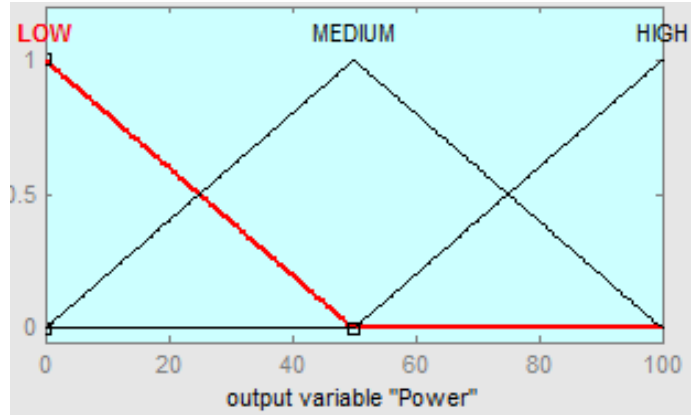

Figure 7. Membership functions of the power output. RESULT AND DISCUSSION

The surface viewer graphs showing the variation of the output power by changing the values of the inputs air velocity and the angle. Three dimensional surface graphs are shown in Figure 8, 9 and 10. 


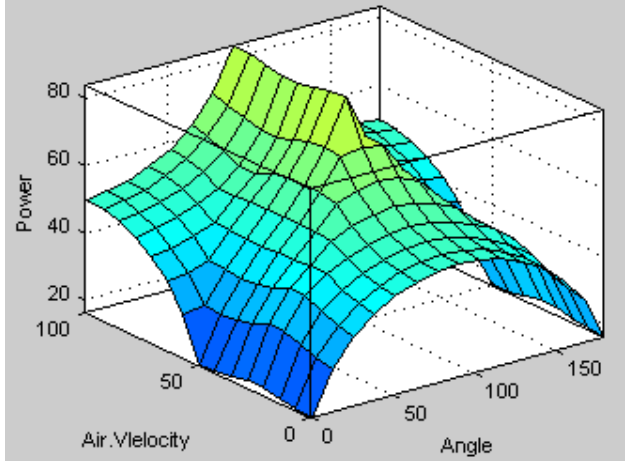

Figure 8. Surface viewer graph for air velocity, angle and power.

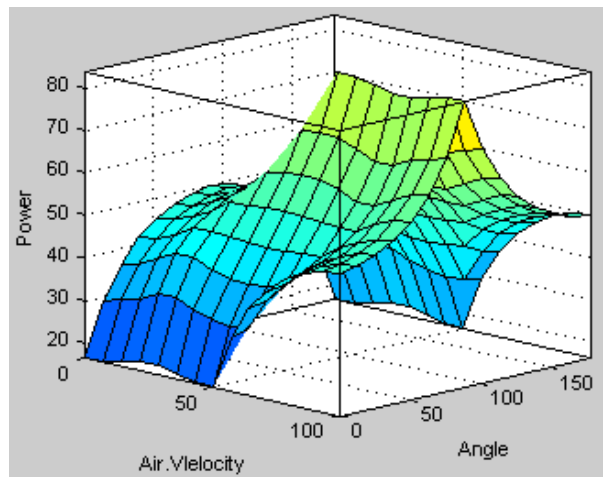

Figure 9. Another view of the surface viewer graph.

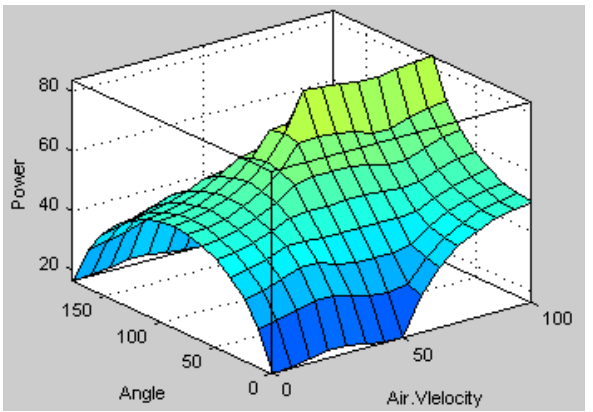

Figure 10. Surface viewer graph of the angle, air velocity and power.

The above surface graphs show that if wind is flowing perpendicular to the surface of the leave or the branch of the tree then it will produce maximum power but for the angle other than $90^{\circ}$ the power will decrease and reach to zero value at 0 or $180^{\circ}$. The other input variable is air velocity. The graph shows that the power will maximum if the air speed will high.

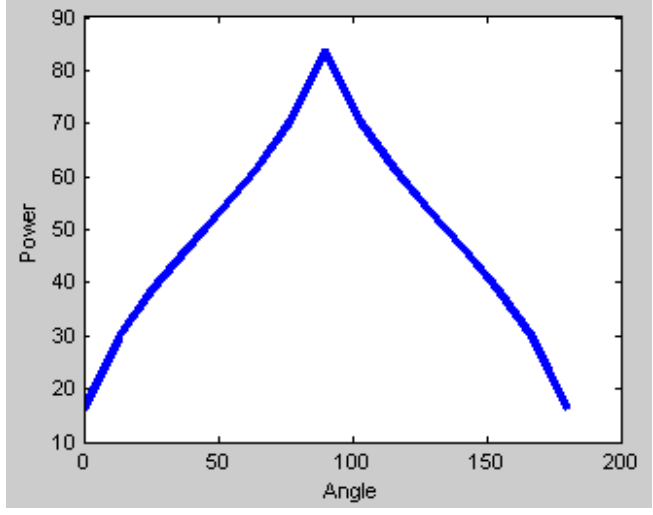

Figure 11. Graph between angle and power.

A two dimensional relation of angle and power is show in Figure 11. This graph shows that by increasing the angle the output power increases and reaches a maximum value at $90^{\circ}$ but if the angle increases from $90^{\circ}$ the power decreases and reaches to zero at $180^{\circ}$.

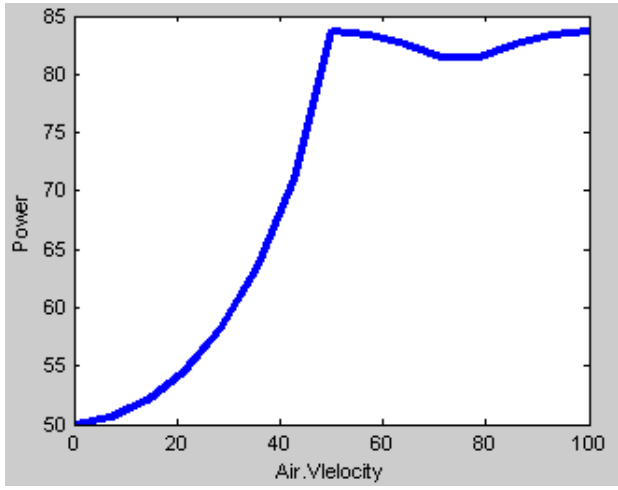

Figure 12. Graph between air velocity and power.

A two dimensional relation of air velocity and power is show in Figure 12. The graph represents that if the value of the air velocity lies between 50 and 100 , the maximum output power will be achieved. This graph also shows that the maximum output power will also be achieved for large values of the air velocity.

ALGORITHM DESIGN FOR THE OUTPUT POWER CONTROLLER SYSTEM

The values of the inputs and output parameters for the design algorithm of fuzzy logic controller are: Air Velocity $=40$, Angle $=106^{\circ}$ and Power $=66$ as shown in Figure 13. 

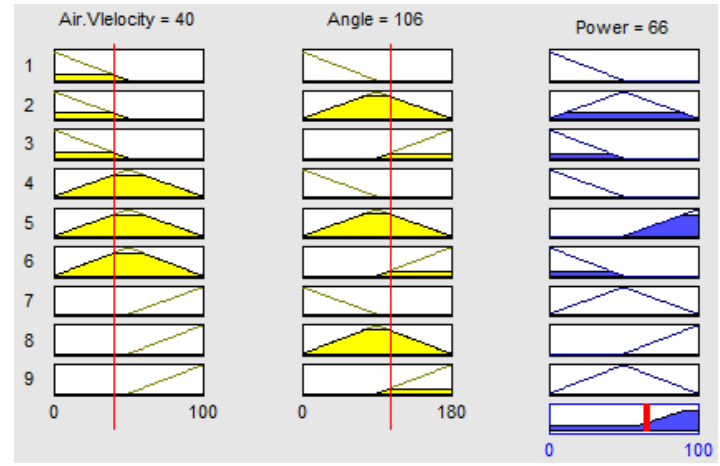

Figure 13. MATLAB Rule Viewer and Simulation Results of the Energy Harvesting System.

Figure 14 shows $\mathrm{mf}_{1}$ and $\mathrm{mf}_{2}$ for air Velocity. It is clear from the Figure 14 that the value of the air velocity (40) lies in region 1 and the region 1 is lying from 0 to 50, therefore, the membership functions for this region are Slow (S) and Fast (F). The values $\mathrm{mf}_{1}$ and $\mathrm{mf}_{2}$ for this region are $\mathrm{mf}_{1}=(50-$ $40) / 50=0.20$ and $\mathrm{mf}_{2}=1-\mathrm{mf}_{1}=1-0.20=0.80$.

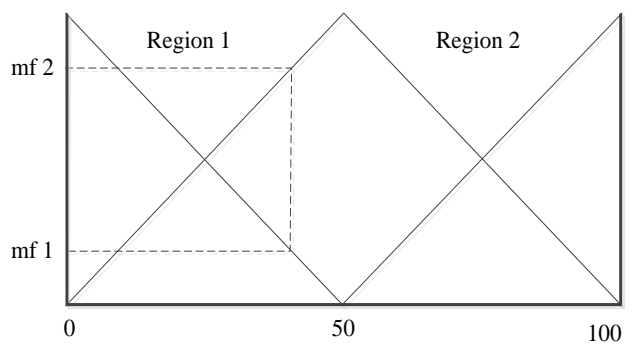

Figure 14. Graph showing the values of the $\mathrm{mf}_{1}$ and $\mathrm{mf}_{2}$ for the air velocity.

Figure 13 shows that value of the Angle $\left(106^{\circ}\right)$ lies in the region 2 which range from 90 to $180^{\circ}$. For this region the membership functions are right angle $(\mathrm{R})$ and obtuse angle (O). The values of the $\mathrm{mf}_{3}$ and $\mathrm{mf}_{4}$ for this region are given as: $\mathrm{mf}_{3}=(180-106) / 90=0.82, \mathrm{mf}_{4}=1-\mathrm{mf}_{3}=1-0.82=$ 0.18. Figure 15 shows $\mathrm{mf}_{3}$ and $\mathrm{mf}_{4}$ for angle 106 .

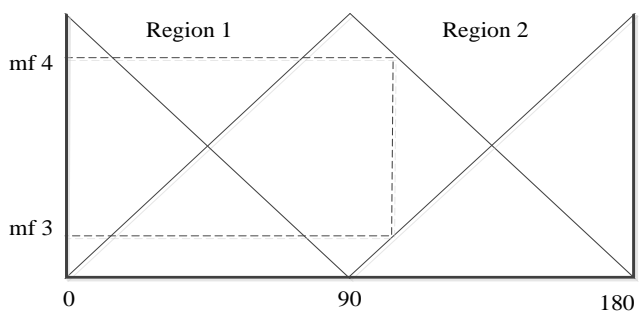

Figure 15. Graph showing the values of the $\mathrm{mf}_{3}$ and $\mathrm{mf}_{4}$ for the angle.

Figure 16 shows $\mathrm{mf5}$ and $\mathrm{mf} 6$ for output power. The value of the output power 66 lies in region 2 and the membership function for this region are Medium (M) and High $(\mathrm{H})$. The values of the membership functions $\mathrm{mf}_{5}$ and $\mathrm{mf}_{6}$ are given below: $\mathrm{mf}_{5}=(100-66) / 50=0.68, \mathrm{mf}_{6}=1-0.68=0.32$

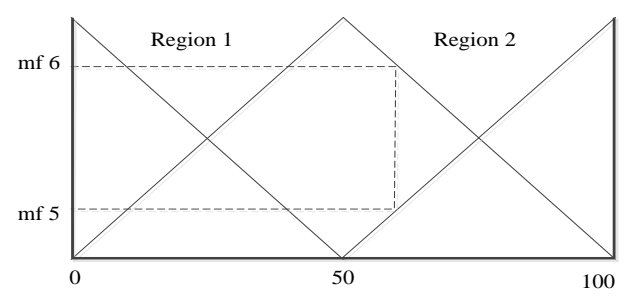

Figure 16. Graph Showing the Values of the $\mathrm{mf}_{5}$ and $\mathrm{mf}_{6}$ for the output power.

Number of active rules $=\mathrm{m}^{\mathrm{n}}$, where $\mathrm{m}$ denotes the membership functions and $\mathrm{n}$ denotes the number of input variables, therefore, the number of rules for the proposed system will be $3^{2}=9$. The defined rules are added in the fuzzy logic inference editor and are given in Figure 17, and the selected rules are given in Table 2.

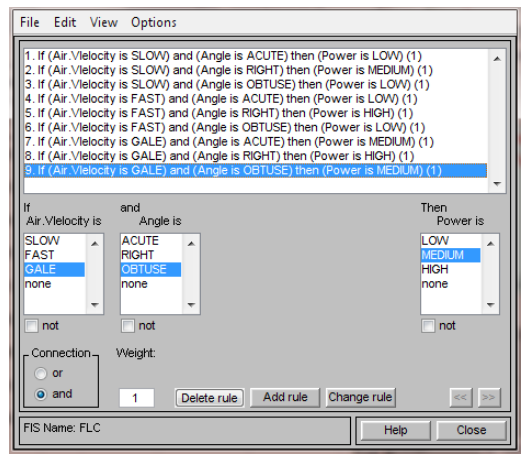

Figure 17. showing the defined rules in the fuzzy logic rules editor.

Table 2. Selected rules.

\begin{tabular}{|c|c|c|c|}
\hline Rules & $\begin{array}{c}\text { Air } \\
\text { Velocity }\end{array}$ & Angle & Power \\
\hline $\mathrm{R}_{1}$ & Slow (S) & Right (R) & Medium (M) \\
\hline $\mathrm{R}_{2}$ & Slow (S) & Obtuse (O) & Low (L) \\
\hline $\mathrm{R}_{3}$ & Fast (F) & Right (R) & High (H) \\
\hline $\mathrm{R}_{4}$ & Fast (F) & Obtuse (O) & Low (L) \\
\hline
\end{tabular}

According to values of input variables (Air Velocity $=40$ and Angle $=106^{\circ}$ ) the selected rules for fuzzy logic controller with singleton values are listed in Table 3 , and the membership function values for the selected rules is shown in Table 4.

Table 3. Singleton values for the proposed system.

\begin{tabular}{|c|c|c|c|c|}
\hline Rules & $\begin{array}{c}\text { Air } \\
\text { Velocity }\end{array}$ & Angle & Power & $\begin{array}{c}\text { Singleton } \\
\text { value (Si) }\end{array}$ \\
\hline $\mathrm{R}_{1}$ & $\mathrm{~S}$ & $\mathrm{R}$ & $\mathrm{M}$ & 0.5 \\
\hline $\mathrm{R}_{2}$ & $\mathrm{~S}$ & $\mathrm{O}$ & $\mathrm{L}$ & 0 \\
\hline $\mathrm{R}_{3}$ & $\mathrm{~F}$ & $\mathrm{R}$ & $\mathrm{H}$ & 1 \\
\hline $\mathrm{R}_{4}$ & $\mathrm{~F}$ & $\mathrm{O}$ & $\mathrm{L}$ & 0 \\
\hline
\end{tabular}


Table 4. Membership functions of the selected rules.

\begin{tabular}{|c|c|}
\hline Rules & Minimum Membership function values \\
\hline $\mathrm{R}_{1}$ & $\mathrm{mf}_{1} \wedge \mathrm{mf}_{3}=0.20 \wedge 0.82=0.20$ \\
\hline $\mathrm{R}_{2}$ & $\mathrm{mf}_{1} \wedge \mathrm{mf}_{4}=0.20 \wedge 0.18=0.18$ \\
\hline $\mathrm{R}_{3}$ & $\mathrm{mf}_{2} \wedge \mathrm{mf}_{3}=0.80 \wedge 0.82=0.80$ \\
\hline $\mathrm{R}_{4}$ & $\mathrm{mf}_{2} \wedge \mathrm{mf}_{4}=0.80 \wedge 0.18=0.18$ \\
\hline
\end{tabular}

Calculations: The output power of the energy harvesting is calculated by using the Mamdani's formula as given in the equation 1:

$$
\mathrm{P}=[\Sigma(\mathrm{Ri} \times \mathrm{Si}) / \Sigma \mathrm{Ri}]
$$

Here the Ri values of the selected rules are taken from the Table 4 and Si the singleton values are taken from the Table 3. The singleton values of the power for membership functions Low, Medium and High are 0.0, 0.5 and 1.0, respectively. Therefore,

$$
\begin{gathered}
\Sigma \mathrm{S}_{\mathrm{i}} \times \mathrm{R}_{\mathrm{i}}=\mathrm{S}_{1} \times \mathrm{R}_{1}+\mathrm{S}_{2} \times \mathrm{R}_{2}+\mathrm{S}_{3} \times \mathrm{R}_{3}+\mathrm{S}_{4} \times \mathrm{R}_{4} \\
=0.5 \times 0.20+0.0 \times 0.18+1 \times 0.80+0.0 \times 0.18=0.90 \\
\Sigma \mathrm{Ri}=\mathrm{R}_{1}+\mathrm{R}_{2}+\mathrm{R}_{3}+\mathrm{R}_{4} \\
=0.20+0.18+0.80+0.18=1.36 \\
\quad \mathrm{P}=[\Sigma \mathrm{Ri} \times \mathrm{Si} / \Sigma \mathrm{Ri}]=0.90 / 1.36=0.6618
\end{gathered}
$$

The calculated and simulated values are compared in the Table 5.

Table 5. Comparison for values

\begin{tabular}{|l|l|}
\hline MATLAB simulated value & 0.6600 \\
\hline Calculated value & 0.6618 \\
\hline Difference & 0.0018 \\
\hline Error in percentage & $0.27 \%$ \\
\hline
\end{tabular}

The observed error between simulated and calculated values is $0.27 \%$, which is a very small value, therefore, the proposed system will performed well in order to produce electricity by the to and fro motion of the leaves and branches of trees when air will blow through them. An energy harvesting with the movement of plant's branches and leaves can be implemented using fuzzy logic based system.

Conclusion: The energy harvesting system based on fuzzy logic is being proposed here. The fuzzy logic controller controls the outputs Power of the energy generator in order to provide the electricity for the wireless system remote control weather station by the process of piezoelectricity. The FL controller of the given system consist of two inputs air velocity and angle and single output power and the Mamdani's model and the AND logic have been applied. The MATLAB simulated value is 0.826 and the calculated value is 0.8125 . Only $1.3 \%$ error is occurred for the output power, which is very small, therefore, the proposed system will perform well. The above results and discussions show that the simulated and theoretical values are in close agreement that verifies the system performance. In future work the presented model will be implemented practically by installing the sensors and the response outputs will be optimized.

\section{REFERENCES}

Cha, Y., W. Chae, H. Kim, H. Walcott, S.D. Peterson and M. Porfiri. 2016. Energy harvesting from a piezoelectric biomimetic fish tail. Renewable Energy 86: 449-458.

Bharani, R. and K.C. Jayasankar. 2015. Yaw Control of Wind Turbine Using Fuzzy Logic Controller, pp.997-1006. In: C. Kamalakannan, L.P. Suresh, S.S. Dash and B.K. Panigrahi (eds.), Power Electronics and Renewable Energy Systems. Springer, India.

Donelan, J.M., Q. Li, V. Naing, J.A. Hoffer, D.J. Weber and A.D. Kuo. 2008. Biomechanical energy harvesting: generating electricity during walking with minimal user effort. Sci. 319: 807-810.

Hu, Y. and Z.L. Wang. 2015. Recent progress in piezoelectric nanogenerators as a sustainable power source in selfpowered systems and active sensors. Nano Energy 14: 3-14.

Hwang, G.T., Y. Kim, J.H. Lee, S. Oh, C.K. Jeong, D.Y. Park, J. Ryu, H. Kwon, S.G. Lee, B. Joung, D. Kim and K.J. Lee. 2015. Self-powered deep brain stimulation via a flexible PIMNT energy harvester. Energy Environ. Sci. 8: $2677-$ 2684.

Ilyas, M.A. and J. Swingler. 2015. Piezoelectric energy harvesting from raindrop impacts. Energy 90: 796-806.

Javed, M.R., A. Amin and P. Azim. 2015. Comparison of standard of living between Pakistan and Bangladesh. Int. J. Asian Soc. Sci. 5: 71-724.

Kamat, P.V. 2007. Meeting the clean energy demand: Nanostructure architectures for solar energy conversion. J. Phys. Chem. C. 111: 2834-2860.

Khoshnevisan, B., S. Rafiee, M. Omid, H. Mousazadeh, S. Shamshirband and S.H.A. Hamid. 2015. Developing a fuzzy clustering model for better energy use in farm management systems. Renew. Sust. Energy Rev. 48: 27-34.

Liu, L.N. 2015. Distribution and dynamics of electron transport complexes in cyanobacterial thylakoid membranes. Biochimica et Biophysica Acta Bioenergicts 1857: 256-265.

Lund, P.D., J. Mikkola and J. Ypya. 2015. Smart energy system design for large clean power schemes in urban areas. J. Cleaner Prod. 103: 437-445.

McGarry, S. and C. Knight. 2011. The potential for harvesting energy from the movement of trees. Sensors 11: 9275-9299.

Peano, F. and T. Tambosso. 2005. Design and optimization of a MEMS electret-based capacitive energy scavenger. J. Microelectromech. Sys. 14: 429-435.

Shafer, M.W., R. MacCurdy, J.R. Shipley, D. Winkler, C.G. Guglielmo and E. Garcia. 2015. The case for energy harvesting on wildlife in flight. Smart Mat. Struc. 24: 25-31.

Suganthi, L., S. Iniyan and A.A. Samuel. 2015. Applications of fuzzy logic in renewable energy systems-a review. Renew. Sust. Energy Rev. 48: 585-607.

Xie, X.D., Q. Wang and S.J. Wang. 2015. Energy harvesting from high-rise buildings by a piezoelectric harvester device. Int. J. Eng. Sci. 93: 1345-1352.

Yasmeen, S. and M.S. Khan. 2013. Automated milk preservation system using fuzzy logic system. J. Anim. Plant Sci. 23: 1477-1481.

Zou, H., H. Chen and X. Zhu. 2015. Piezoelectric energy harvesting from vibrations induced by jet-resonator system. Mech. 26:29-35. 